\title{
Evaluation of metabolomics behavior of human colon cancer HT29 cell lines treated with ionic liquid graviola fruit pulp extract
}

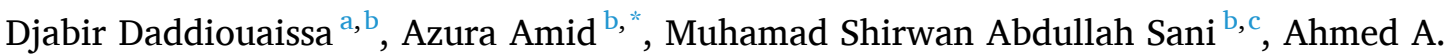 \\ M. Elnour ${ }^{\mathrm{a}, \mathrm{b}}$ \\ a Biotechnology Engineering Department, Kulliyyah of Engineering, International Islamic University, Malaysia (IIUM), P. O. Box 10, Gombak, 50728, Kuala Lumpur, \\ Malaysia \\ ${ }^{\mathrm{b}}$ International Institute for Halal Research and Training (INHART), Level 3, KICT Building, International Islamic University Malaysia (IIUM), Jalan Gombak, 53100, \\ Kuala Lumpur, Malaysia \\ ${ }^{\mathrm{c}}$ Konsortium Institut Halal IPT Malaysia, Ministry of Higher Education, Block E8, Complex E, Federal Government Administrative Centre, 62604, Putrajaya, Malaysia
}

\section{A R T I C L E I N F O}

\section{Keywords:}

Colon cancer (HT29)

Graviola (Annona muricata)

GC-TOFMS

Metabolomics

Principal components analysis

\begin{abstract}
A B S T R A T
Ethnopharmacological relevance: Medicinal plants have been used by indigenous people across the world for centuries to help individuals preserve their wellbeing and cure diseases. Annona muricata L. (Graviola) which is belonging to the Annonaceae family has been traditionally used due to its medicinal abilities including antimicrobial, anti-inflammatory, antioxidant and cancer cell growth inhibition. Graviola is claimed to be a potential antitumor due to its selective cytotoxicity against several cancer cell lines. However, the metabolic mechanism information underlying the anticancer activity remains limited.

Aim of the study: This study aimed to investigate the effect of ionic liquid-Graviola fruit pulp extract (IL-GPE) on the metabolomics behavior of colon cancer (HT29) by using an untargeted GC-TOFMS-based metabolic profiling. Materials and methods: Multivariate data analysis was used to determine the metabolic profiling, and the ingenuity pathway analysis (IPA) was used to predict the altered canonical pathways after treating the HT29 cells with crude IL-GPE and Taxol (positive control).

Results: The principal components analysis (PCA) identified 44 metabolites with the most reliable factor loading, and the cluster analysis (CA) separated three groups of metabolites: metabolites specific to the non-treated HT29 cells, metabolites specific to the treated HT29 cells with the crude IL-GPE and metabolites specific to Taxol treatment. Pathway analysis of metabolomic profiles revealed an alteration of many metabolic pathways, including amino acid metabolism, aerobic glycolysis, urea cycle and ketone bodies metabolism that contribute to energy metabolism and cancer cell proliferation.

Conclusion: The crude IL-GPE can be one of the promising anticancer agents due to its selective inhibition of energy metabolism and cancer cell proliferation.
\end{abstract}

\section{Introduction}

Annona muricata L. (variety DB3), also named as Graviola, belongs to the Annonaceae family that gained considerable attention over the last period due to its medicinal abilities. Graviola tree grows in the warmest tropical areas around the world. Its edible fruit is large, heart-shaped and dark green. It has a sweet flesh and typically flavoured pulp that can be consumed as an ingredient in the processing of several foods and beverages. Ethnobotanical studies have stated that all parts of the Graviola tree are being used in alternative therapies, specifically the fruit which is used to remove worms and parasites (Yajid et al., 2018), to treat fever (Taylor, 2002), as well as kidney and liver infections (Coe, 2008), hypertension (Samuel et al., 2010) and cancer prevention (Dal Molin et al., 2012; Monigatti et al., 2013). The common use of Graviola in anticancer therapy was reported ethnobotanically maybe because of its selective cytotoxicity (George et al., 2012; Monigatti et al., 2013). This selectivity was documented by many studies showing that the Graviola fruit extract was selectively toxic to tumour cells than normal cells (Betancur-Galvis et al., 1999; Dai et al., 2011; Gavamukulya et al., 2014). Graviola has enormous potential anticancer compounds known

\footnotetext{
* Corresponding author.

E-mail address: azuraamid@iium.edu.my (A. Amid).
} 
as acetogenins (AGEs), which play a vital role in many types of cancer. Several reports have documented the significant cytotoxicity of crude extracts and AGEs isolated from various parts of the Graviola tree against different cancer cell lines (Dai et al., 2011; Paul et al., 2013). Nonetheless, few of these studies have demonstrated the properties of the fruit pulp and its mechanisms against cancer cell proliferation.

Cancer development involves several pathways and phases, leading to faster growth than normal cells and also shows an increase in glucose metabolism and lactate production (Martinez-Outschoorn et al., 2017). From a genetic point of view, colon cancer is one of the most prevalent neoplasms, and it remains the second most common cause of cancer-related death (Siegel et al., 2020), suggesting that the conventional therapies are not eradicating the whole cancer cells which lead to metastasis.

Metabolomics study of a targeted tissue reflects the metabolism perturbation more precisely than the biofluidic system (blood plasma and urine), which are utilised in conventional metabolomic research. Hence, the study of metabolites has facilitated the determination of the appropriate markers of toxicity and drug performance; as well as a significant achievement of prognosis or diagnosis of disease (Cao et al., 2011). Metabolomics study is considered influential in the field of Omics research that can attain a thorough overview of the perturbed metabolome in a biological organism (Ramirez et al., 2013). Metabolic profiling can offer a clear understanding of the pharmacological activity, functional aspects and drug efficacy through underlying biochemical alterations in reaction to drug stimulation or genetic manipulation (Fernie et al., 2004; Weiner et al., 2018). In general, cancer cells are known to have many specific metabolic characteristics, including high energy metabolism, high amino acid levels and fatty acid synthesis (Zhao et al., 2013). Thus, many studies aimed to investigate cell metabolism to determine possible biomarkers for diagnosis of cancer and its response to drug treatment (Tan et al., 2012). Relevant approaches, including cell harvesting, metabolism quenching, metabolite extraction and data analysis and measurements, are used to facilitate metabolomics studies of cultured cells (Alessandro and Zolla, 2012; Zhao et al., 2013). Nowadays, the three primary techniques that are used to characterise metabolic profiling are nuclear magnetic resonance (NMR), gas chromatography-mass spectrometry (GC-MS) and liquid chromatography-mass spectrometry (LC-MS) (Li et al., 2012). Among these techniques, GC-MS has excellent benefits including a variety of uses in the global and targeted analysis, high resolution, the availability of mass spectrum reference libraries. Moreover, Ingenuity Pathway Analysis (IPA) software (QIAGEN Inc) is quantitative genomics, transcriptomics, proteomics and metabolomics analysis tool that provides the significance of the uploaded data and determines new biomarker candidates within a biological system. IPA is commonly used in the scientific research community for its analysis and interpretation of omics data (Kouznetsova et al., 2019). This study aimed to explore and evaluate the metabolic alterations and mechanism of the crude IL-GPE treatment on in vitro colon cancer HT29 cells by using multiple analytical approaches.

\section{Material and methods}

\subsection{Chemicals and reagents}

All chemicals and reagents utilised in this research had a laboratorygrade. For extraction, the ionic liquid, one-butyl-3-methylimidazolium chloride [C4MIM] [Cl] (96\%) was purchased from ALFA, (USA). For cell culture, Dulbecco's modified Eagle's medium (DMEM), fetal bovine serum (FBS) as well as penicillin/streptomycin (pen/strip) were obtained from GIBCO $®$ (Invitrogen, USA). Also, Taxol, myristic acid 13C, 99\% and N, O-bis(trimethylsilyl)-trifluoroacetamide (BSTFA) were purchased from Sigma-Aldrich (Germany). Organic solvents, including analytical grades of acetonitrile $(\mathrm{CH} 3 \mathrm{CN})$, chloroform $(\mathrm{CHCl} 3)$ and methanol $(\mathrm{MeOH})$ were obtained from HmbG Chemical (Germany).

\subsection{Fruit preparation}

Graviola fruit pulp collection and preparation were following the previous publication (Daddiouaissa et al., 2020), in which, the fruit was collected from the Adikafirdaus Farm located in Perak $\left(4.5921^{\circ} \mathrm{N}\right.$, $101.0901^{\circ} \mathrm{E}$ ), Malaysia. The fruit specimen variety DB3 was marked and deposited in the KAED, International Islamic University Malaysia, with voucher number KAED/HBL/S1A047/2018/706. The plant's name was reviewed using the website (www.theplantlist.org). The fruit was washed, the pericarp and seeds were discarded, and the pulp was freeze-dried for $72 \mathrm{~h}$ using a freeze dryer (Christ Alpha, Germany). The freeze-dried pulp was then ground using a commercial dry blender into a powder form and deposited at $4{ }^{\circ} \mathrm{C}$ for further analysis (Gyamfi et al., 2011).

\subsection{Fruit pulp compounds extraction}

The pulp of Graviola fruit was extracted as described in the previous paper (Daddiouaissa et al., 2019). In short, the fruit pulp (1 g) was mixed with $20 \mathrm{~mL}$ of $0.5 \mathrm{~mol} / \mathrm{L}$ of [C4MIM] [Cl] reagent. The suspension was then heated for $3 \mathrm{~min}$ in a microwave oven under $700 \mathrm{~W}$ irradiation power. The suspension was then filtered to a test tube using a Whatman $3 \mathrm{~mm}$ filter paper. Finally, the crude filtrate (IL-GPE) was lyophilised for $72 \mathrm{~h}$ using the freeze dryer (Christ Alpha, Germany).

\subsection{Treatment of HT29 cancer cells using IL-GPE}

The colon cancer HT29 cell lines were purchased from American Type Culture Collection (ATCC $®$ HTB-38). These cells were inoculated into $5 \mathrm{~mL}$ of DMEM complemented with $10 \%$ FBS and 1\% pen/strip in $25 \mathrm{~cm}^{2}$ T-flask until almost $70 \%$ confluency. To treat the HT29 cancer cells, the old medium was changed with individual fresh medium (Daddiouaissa et al., 2019) accompanied with: (1) crude IL-GPE solution at $10.56 \mu \mathrm{g} / \mathrm{mL}$, (2) Taxol at $1.22 \mu \mathrm{g} / \mathrm{mL}$ as a positive control and (3) DMSO at $0.2 \%$ as a negative control, and incubated for $48 \mathrm{~h}$ at $37^{\circ} \mathrm{C}$ in a $5 \% \mathrm{CO}_{2}$ incubator.

\subsection{Quenching of mammalian cell metabolites}

After the treatment of HT29 cancer cells, the culture medium was discarded, and the cells were quenched as described previously by Liu et al. (2018). In brief, the cells' surface was rinsed gently by adding 10 $\mathrm{mL}$ of deionised water, the flask containing the rinsed cells was briefly rocked, and the cells were quenched by adding $10 \mathrm{~mL}$ of liquid nitrogen to the cell surface for $5 \mathrm{~s}$. Then, the cells were stored in a $-80^{\circ} \mathrm{C}$ freezer for metabolite extraction. To ensure a standardisation result, only cells stored in $-80{ }^{\circ} \mathrm{C}$ at $\leq 7 \mathrm{~d}$ were subjected to metabolite extraction.

\subsection{Metabolite extraction}

The cells were transferred into $1.5 \mathrm{~mL}$ vials and extracted with a 1.2 mL solvent mixture of $\mathrm{CH}_{3} \mathrm{Cl}: \mathrm{MeOH}: \mathrm{H}_{2} \mathrm{O}$ at 20:50:20 (v/v/v) ratio (Liu et al., 2018) with the internal standard of myristic acid at $2 \mu \mathrm{g} / \mathrm{mL}$ on ice (Cao et al., 2011). Then, the cells extracts were vortexed for $5 \mathrm{~min}$, incubated on ice for $15 \mathrm{~min}$ and sonicated for $15 \mathrm{~min}$ using an ultrasonic water bath (JAC Ultrasonic 4020, Korea). The cell extracts were incubated again on ice and then centrifuged at $15,000 \mathrm{G}$-force at $4{ }^{\circ} \mathrm{C}$. The supernatants were relocated to the other set of tubes and then centrifuged again with the similar conditions mentioned before (Mishra et al., 2017). Finally, the supernatants were freeze-dried for $72 \mathrm{~h}$ and stored at $4{ }^{\circ} \mathrm{C}$ for analysis by GC-TOFMS.

\subsection{Sample preparation and GC-TOFMS analysis}

For GC-TOFMS analysis, the freeze-dried supernatants were silylated in sealed vials using $1 \mathrm{~mL}$ mixture of BSTFA and acetonitrile at 40:60 
ratio, vortexed for $1 \mathrm{~min}$ and then incubated for $1 \mathrm{~h}$ at $60{ }^{\circ} \mathrm{C}$. Silyl derivatisation is a standard method to increase the volatility of the chemical compounds and detectability of gas chromatography analysis (Jang et al., 2012). In this study, the GC-TOFMS analysis of the metabolites was carried out by using an Agilent-Technologies 7890 A GC system which was equipped with an Agilent-Technologies 7693 mass spectrometer system detector (Agilent Technologies, USA). The method of Muhamad et al. (2017) was adopted with slight modifications. An approximate of $1 \mu \mathrm{L}$ was injected into the $225^{\circ} \mathrm{C}$ inlets at a ratio of $1: 10$ under splitless mode. The carrier gas, helium was used constantly at a flow rate of $1.2 \mathrm{~mL} / \mathrm{min}$. An HP-5 MS capillary column $(30 \mathrm{~m} \times 0.25$ $\mathrm{mm}$, with a film thickness of $0.25 \mu \mathrm{m}$ ) was utilised for separation. The GC oven temperature was programmed at $80^{\circ} \mathrm{C}$ and maintained for 2 min; then increased to $240{ }^{\circ} \mathrm{C}$ at $5{ }^{\circ} \mathrm{C} / \mathrm{min}$ for $5 \mathrm{~min}$, and raised to $300^{\circ} \mathrm{C}$ at a rate of $3{ }^{\circ} \mathrm{C} / \mathrm{min}$ for $5 \mathrm{~min}$. The temperature MS transfer line was set at $300{ }^{\circ} \mathrm{C}$. The separated metabolites were detected by a set-up mass spectrometer at $70 \mathrm{eV}$ electron energy and a mass range of $\mathrm{m} / \mathrm{z} 50-550$. The detected compounds were identified by comparing their mass spectra and retention time with those of the standard compounds of the National Institute of Standard (NIST) library in which, only metabolites that have the similarity of more than $70 \%$ with the standard mass spectra in the NIST V.2.0 library were chosen for further analysis (Maratu et al., 2020). The peak area of individual metabolites has been normalised to the peak area of the internal standard (myristic acid) based on analytical ion chromatograms to quantify the identified metabolites (Xiao et al., 2011).

\subsection{Multivariate data analysis}

Multivariate data analysis (MVA) is a statistical tool used to evaluate data derived from more than one variable. The MVA can be utilised to interpret and analyse data stored in different data sets and provides meaningful results. This approach was used to provide a table summary in a database often referred to as a factor analysis that reads strong patterns in data such as clusters, trends, outliers and their recurrence forming a pattern. In this study, data pre-processing was carried out prior to the MVA entailing principal component analysis (PCA) and agglomeration hierarchical clustering (AHC).

\subsubsection{Data preprocessing}

The data matrix of different metabolites from control and the treated HT29 cancer cells was analysed by MVA using XLSTAT 2014 (Addinsoft, USA). The test of sampling adequacy, Kaiser-Meyer-Olkin (KMO) was carried out to check the adequacy of data before applying the PCA and AHC. Also, Bartlett's test of sphericity was employed to investigate the correlation among the metabolites at (p-value $<0.005$ ) (Gagaoua et al., 2018).

\subsubsection{Principal component analysis}

The PCA was applied to identify any alteration in the metabolite profile after treatment with crude IL-GPE and Taxol, and discriminate the sample groups based on the significant metabolites that contributed to each sample group (Ringnér, 2008) at $\mathrm{p}<0.05$. For visual analysis, two-dimensional axes which represented two principal perpendicular components (PCs) were established. Metabolites corresponded to the PC were assigned with factor loading (FL), and the FL value indicated (1) contribution of the metabolites to the PC and (2) correlations between the metabolites. Only metabolites with $\mathrm{FL} \geq|0.7|$ were selected in this study (Granato et al., 2018).

\subsubsection{Agglomeration hierarchical clustering}

Agglomeration hierarchical clustering, based on complete linkage on agglomeration method and Euclidean distance as a dissimilarity index, was conducted to evaluate statistical differences between metabolites at a significant level of 0.05 ( $p<0.05)$. The samples were grouped into cluster hierarchy according to similar metabolite profiles (Dash et al.,
2003). To decide the groups to be merged, a measure of dissimilarity between the samples was computed using a useful metric and a linkage criterion, which defined the dissimilarity of the clusters as a function of the pairwise distances in the sets.

\subsection{Metabolic pathway analysis}

The identified metabolites by PCA which had FL $>|0.7|$, were chosen for metabolic pathway analysis. To infer the potential biological effect related to the metabolic alteration, the HMDB IDs and $\log 2$ (Fold Change) of 45 chosen metabolites were input to Ingenuity Pathway Analysis (IPA) software (QIAGEN, USA) for biological interpretation. Next, the networks between pathways at p-value $<0.05$ after statistical analysis using Fisher's exact test (Minitab software, USA) were drawn using commercial database Kyoto Encyclopaedia of Genes and Genomes (KEGG) to determine the potentially affected pathways for the candidate biomarkers after HT29 cells exposed to the crude IL-GPE.

\section{Results}

\subsection{Overall view of metabolomic profiles}

The GC-TOFMS metabolomics data of intracellular metabolites that had been extracted from untreated HT29 (control) and the treated HT29 cells with the crude IL-GPE and Taxol were utilised to develop multivariate data analyses; particularly the AHC, the PCA and the pathway analysis (PA). From a total of 396 metabolites that were detected from the control and the treated HT29 cells, only 51 metabolites (Table 1) were chosen for further analysis based on their similarity of more than $70 \%$ with the standard mass spectra in the NIST V.2.0 library. The KMO measures of sampling adequacy of 0.675 with a highly significant Bartlett's test of sphericity (p-value $<0.0001$ ) indicating the adequacy of the data for MVA and the presence of correlations among the metabolites.

The non-treated HT29 cells were characterised by the presence of tricosadiynoic acid $(21.02 \%)$ having the highest percentage area, followed by lactic acid (15.30\%) and butanol (12.77\%). While the treated HT29 cells with crude ILGPE were shown the presence of carbohydrazide (18.86\%), trimethylsilylmethanol (15.45\%) and lactic acid (5.24\%). Besides, the treated HT29 cells with Taxol were characterised by the presence of carbohydrazide (3.56\%), butane $(2.77 \%)$ and carbamic acid ethylnitroso (2.70\%).

\subsection{Principal components analysis}

PCA of the whole set of the non-treated HT29 cells (NT-HT29), ILGPE-treated HT29 (IL-GPE-HT29) and Taxol-treated HT29 cells (Taxol-HT29) were performed using XLSTAT 2014. Three groups were mainly produced in the score scatter plot with a gradient generated by the PC1 and PC2 led to a distinct separation in the observation plot (Fig. 1) of the non-treated HT29 from the treated HT29 with crude ILGPE and Taxol that accounted for $85.89 \%$ of the total variance.

Among the 51 metabolites that were included in the analysis, 44 metabolites had shown strong correlations among the metabolites with the FL between $-0.7<\mathrm{R}<-1$ and $0.7<\mathrm{R}<1$ (Fig. 2). Upon illustrating metabolite distributions, the major metabolites that had synergistic effects on PC1 dimension were acetic acid hydrazide, tetrafluorohydrazine, lactic acid, diethylamino trimethylsilane, chlorophenyl ethylamine, phosphinous chloromethyl chloride, heptyl dioxolane, diethyl azodicarboxylate, acetylglycine, diethyl carbamate, butanol, alanine, butane, diethylene glycol, methylheptadecane, octamethyl-dioxa disilaoctane, hexadecanal cyclic ethylene acetal, phosphoric acid, palmitelaidic acid, hexadecanoic acid, octadecadiynoic acid, octadecynoic acid, octadecenoic acid, tricosadiynoic acid, cyclooctasiloxane hexadecamethyl. In contrast, metabolites that had antagonistic effects were propadiene-dione, butynol, oxopropanoate. On PC2, 
Table 1

The identified metabolites and their fold changes after treating HT29 cancer cells with the crude IL-GPE and Taxol.

\begin{tabular}{|c|c|c|c|c|c|c|c|c|}
\hline No. & Metabolites name & $\begin{array}{l}\text { Non-treated } \\
\text { HT29 } \\
\text { Area \% }\end{array}$ & $\begin{array}{l}\text { ILGPE-treated } \\
\text { HT29 } \\
\text { Area \% }\end{array}$ & $\begin{array}{l}\text { Fold Change Log2 } \\
\text { (Ratio) }\end{array}$ & $\begin{array}{l}\mathrm{P} \\
\text { value }\end{array}$ & $\begin{array}{l}\text { Taxol-treated } \\
\text { HT29 } \\
\text { Area \% }\end{array}$ & $\begin{array}{l}\text { Fold Change Log } 2 \\
\text { (Ratio) }\end{array}$ & $\begin{array}{l}\mathrm{P} \text { - } \\
\text { value }\end{array}$ \\
\hline 1 & Chloromethane & 0 & 0 & 0 & 1 & 1.04 & 1.03 & 0.001 \\
\hline 2 & Tetraborane & 0 & 0 & 0 & 1 & 1.42 & 1.27 & 0 \\
\hline 3 & Propadiene-dione & 0 & 0.78 & 0.83 & 0.042 & 0.91 & 0.93 & 0.024 \\
\hline 4 & Oxadiazole & 0 & 0 & 0 & 1 & 0.92 & 0.94 & 0.001 \\
\hline 5 & Butynol & 0 & 2.943 & 1.97 & 0.001 & 2.57 & 1.83 & 0.001 \\
\hline 6 & Thiocyanic acid & 0 & 4.539 & 2.46 & 0 & 0 & 0 & 1 \\
\hline 7 & Acetic acid hydrazide & 7.26 & 1.33 & -1.82 & 0.017 & 2.46 & -1.25 & 0.039 \\
\hline 8 & Hydroxyacetic acid hydrazide & 0 & 0 & 0 & 1 & 1.27 & 1.18 & 0.016 \\
\hline 9 & Carbohydrazide & 8.55 & 18.86 & 1.05 & 0.053 & 3.56 & -1.06 & 0.29 \\
\hline 10 & Tetrafluorohydrazine & 0.55 & 0 & -0.64 & 0 & 0 & -0.64 & 0 \\
\hline 11 & Lactic acid & 15.30 & 5.24 & -1.38 & 0.012 & 1.63 & -2.62 & 0.003 \\
\hline 12 & Trimethylsilylmethanol & 0 & 15.45 & 4.04 & 0 & 0 & 0 & 1 \\
\hline 13 & Ethyl trifluoroacetate & 0 & 0 & 0 & 1 & 0.81 & 0.86 & 0.011 \\
\hline 14 & Diethylamino trimethylsilane & 4.68 & 0 & -2.51 & 0 & 0 & -2.50 & 0 \\
\hline 15 & Carbamic acid, ethylnitroso & 3.19 & 0 & -2.06 & 0.001 & 2.70 & -0.17 & 0.401 \\
\hline 16 & Butoxytrimethylsilane & 0 & 0 & 0 & 1 & 1.68 & 1.46 & 0.014 \\
\hline 17 & Pentafluoro-oxazetidine & 0 & 0 & 0 & 1 & 1.56 & 1.35 & 0.001 \\
\hline 18 & Chlorophenyl ethylamine & 10.36 & 0 & -3.50 & 0.011 & 0 & -3.50 & 0.011 \\
\hline 19 & Oxalic acid & 0 & 0 & 0 & 1 & 0.99 & 0.99 & 0 \\
\hline 20 & Oxopropanoate & 0 & 0.25 & 0.32 & 0.109 & 0.36 & 0.44 & 0.036 \\
\hline 21 & Dichlorospiro hexan-one & 0 & 1.49 & 1.31 & 0.003 & 0 & 0 & 1 \\
\hline 22 & Methoxyamphetamine & 0.32 & 0.56 & 0.23 & 0.026 & 0 & -0.40 & 0.007 \\
\hline 23 & Dimethoxybenzylamine & 0 & 3.18 & 2.06 & 0.001 & 0 & 0 & 1 \\
\hline 24 & Phosphinous chloride, (chloromethyl) & 0.91 & 0 & -0.94 & 0.009 & 0 & -0.94 & 0.009 \\
\hline 25 & Dioxolane, heptyl & 0.53 & 0 & -0.62 & 0.097 & 0 & -0.62 & 0.097 \\
\hline 26 & Diethyl azodicarboxylate & 8.90 & 3.61 & -1.10 & 0.151 & 1.68 & -1.88 & 0.066 \\
\hline 27 & Ethyl-methyldecane & 0 & 0.64 & 0.71 & 0 & 0 & 0 & 1 \\
\hline 28 & Acetylglycine & 1.42 & 0 & -1.27 & 0.132 & 0 & -1.27 & 0.132 \\
\hline 29 & Diethyl carbamate & 3.64 & 0 & -2.21 & 0 & 0 & -2.21 & 0 \\
\hline 30 & Butanol & 12.77 & 0 & -3.78 & 0.016 & 0 & -3.78 & 0.016 \\
\hline 31 & Hexadecane & 0 & 0.39 & 0.48 & 0.001 & 0 & 0 & 1 \\
\hline 32 & 1-Alanine & 1.56 & 0 & -1.36 & 0.019 & 0 & -1.36 & 0.019 \\
\hline 33 & Butane & 5.08 & 0 & -2.60 & 0 & 2.77 & -0.68 & 0.015 \\
\hline 34 & Aminobutyric acid & 0 & 0 & 0 & 1 & 0.49 & 0.57 & 0.003 \\
\hline 35 & Diethylene glycol & 3.91 & 0 & -2.29 & 0.002 & 1.25 & -1.12 & 0.014 \\
\hline 36 & Hexafluoropropan-one & 0 & 9.66 & 3.41 & 0.023 & 0 & 0 & 1 \\
\hline 37 & Methylheptadecane & 1.21 & 0.41 & -0.64 & 0.123 & 0 & -1.14 & 0.034 \\
\hline 38 & Undecenoic acid & 1.25 & 2.32 & 0.55 & 0.003 & 0 & -1.17 & 0.001 \\
\hline 39 & Octamethyl-dioxa disilaoctane & 0.96 & 0 & -0.97 & 0 & 0 & -0.97 & 0 \\
\hline 40 & Methyldodecyl oxy & 0.76 & 0.62 & -0.12 & 0.743 & 0 & -0.81 & 0.116 \\
\hline 41 & $\begin{array}{l}\text { Dimethyloxiran-ylmethyl dimethylocta- } \\
\text { dienyl }\end{array}$ & 0 & 0.61 & 0.69 & 0.015 & 0 & 0 & 1 \\
\hline 42 & Malonic acid & 0 & 1.12 & 1.08 & 0 & 0 & 0 & 1 \\
\hline 43 & Phosphoric acid & 2.33 & 0 & -1.73 & 0 & 0 & -1.73 & 0 \\
\hline 44 & Palmitelaidic acid & 2.90 & 0 & -1.96 & 0 & 0 & -1.96 & 0 \\
\hline 45 & Hexadecanoic acid & 2.80 & 0.87 & -1.02 & 0.145 & 0 & -1.92 & 0.051 \\
\hline 46 & Octadecadiynoic acid & 3.20 & 0 & -2.07 & 0.001 & 0 & -2.07 & 0.001 \\
\hline 47 & Octadecynoic acid & 1.97 & 0 & -1.57 & 0 & 0 & -1.57 & 0 \\
\hline 48 & Octadecenoic acid & 5.17 & 1.09 & -1.55 & 0.017 & 0.87 & -1.71 & 0.014 \\
\hline 49 & Tricosadiynoic acid & 21.02 & 0 & -4.46 & 0.004 & 0.80 & -3.61 & 0.005 \\
\hline 50 & Glucopyranose pentakis & 0 & 0.77 & 0.83 & 0.008 & 0 & 0 & 1 \\
\hline 51 & Cyclooctasiloxane hexadecamethyl & 2.25 & 0 & -1.70 & 0.009 & 0 & -1.70 & 0.009 \\
\hline
\end{tabular}

metabolites that had synergistic effects were thiocyanic acid, carbohydrazide, trimethylsilylmethanol, dichlorospiro hexan-one, methoxyamphetamine, dimethoxybenzylamine, ethyl-methyldecane, hexadecane, hexafluoropropan-one, undecenoic acid, dimethyloxiranylmethyl dimethylocta-dienyl, malonic acid, glucopyranose pentakis, while metabolites that had antagonistic effects were chloromethane, tetraborane, oxadiazole, hydroxyacetic acid hydrazide, ethyl trifluoroacetate, carbamic acid, ethylnitroso, butoxytrimethylsilane, pentafluoro-oxazetidine, oxalic acid and aminobutyric acid.

\subsection{Agglomeration hierarchical clustering}

In this section, (AHC) was performed to determine similarities of samples based on the linkage as the agglomeration method and Euclidean distance (ED) as a dissimilarity index (Xiao et al., 2011) and confirming the generated groups by the PCA. The similarity of the samples was depicted by the AHC dendrogram (Fig. 3), which corroborated three groups entailing NT-HT29, Taxol-HT29 and IL-GPE-HT29 as yielded by the PCA. These groups were differentiated at the dissimilarity of $750 \mathrm{ED}$ as denoted by the horizontal dotted line. It indicated that the non-treated HT29 cells have a significant dissimilarity of about 2285 ED with the treated ILGPE-HT29 cells. Furthermore, the non-treated HT29 and IL-GPE treated-HT29 were distinguished at 986 $\mathrm{ED}$, supporting the dissimilarity in the metabolic pathways as effected by the ILGPE.

\subsection{Ingenuity pathway analysis of HT29 cells metabolomic profile}

To understand the possible biological effects which are associated with metabolic changes in HT29 intracellular after exposure to the crude IL-GPE, the IPA selected 29 out of 44 metabolites to be the significant biomarkers in the treated HT29 with crude IL-GPE (Table 2). The IPA 


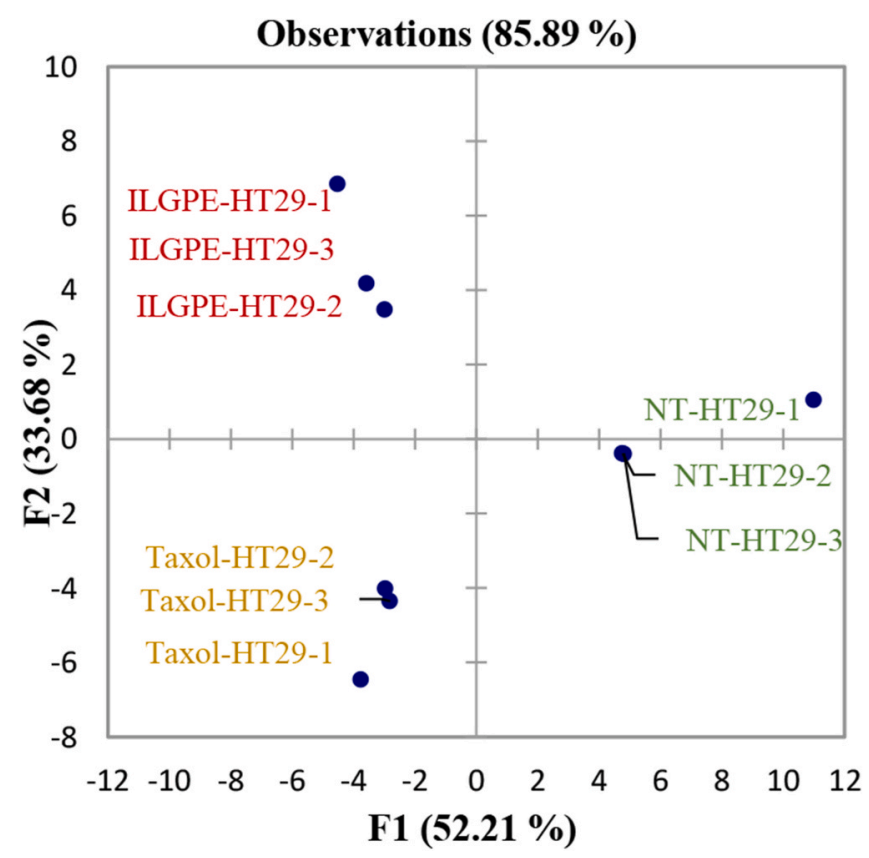

Fig. 1. Principal component analysis (PCA) of intracellular metabolites extracted from the non treated HT29 (control) and the treated HT29 cells with crude IL-GPE and Taxol. also predicted the impact of the treatment on molecular and cellular functions in which, cell death and survival, energy production, molecular transport, cellular compromise and nucleic acid metabolism were the most significantly altered functions.

IPA also predicted the most significantly $(\mathrm{p}<0.05)$ altered canonical pathways after treatment with crude IL-GPE. The downregulation of several amino acids has led to a predicted alteration in the specific amino acid metabolism pathways such as alanine biosynthesis/degradation, glycine biosynthesis, methyl thio propionate biosynthesis, adenosyl-L-methionine biosynthesis, L-cysteine degradation. Aerobic glycolysis altered after acetyl-CoA biosynthesis inhibition, and activation of the lactate. Urea cycle, folate transformations, methylglyoxal degradation and thiosulfate disproportionation were also altered.

\section{Discussion}

Cancer is commonly treated with chemotherapy-based drugs such as paclitaxel (Taxol), doxorubicin, topotecan and cisplatin. However, these treatments are considered to have significant adverse effects on patient's health due to their potential to destroy healthy tissues (Magadi et al., 2015). Hence, searching for new anticancer agents that are safe for human health is essential. Graviola fruit pulp extract has a potent antitumor effect toward several cancer cells, which creates great interest in further explorations of the mechanisms underlying its antiproliferative activity (Daddiouaissa and Amid, 2018). Previous research reported that the crude IL-GPE induced apoptosis and necrosis in breast adenocarcinoma MCF-7 cell lines and caused G0/G1 phase cell cycle arrest (Daddiouaissa et al., 2019) and does not cause toxicity using the zebrafish model (Daddiouaissa et al., 2020). Numerous studies have

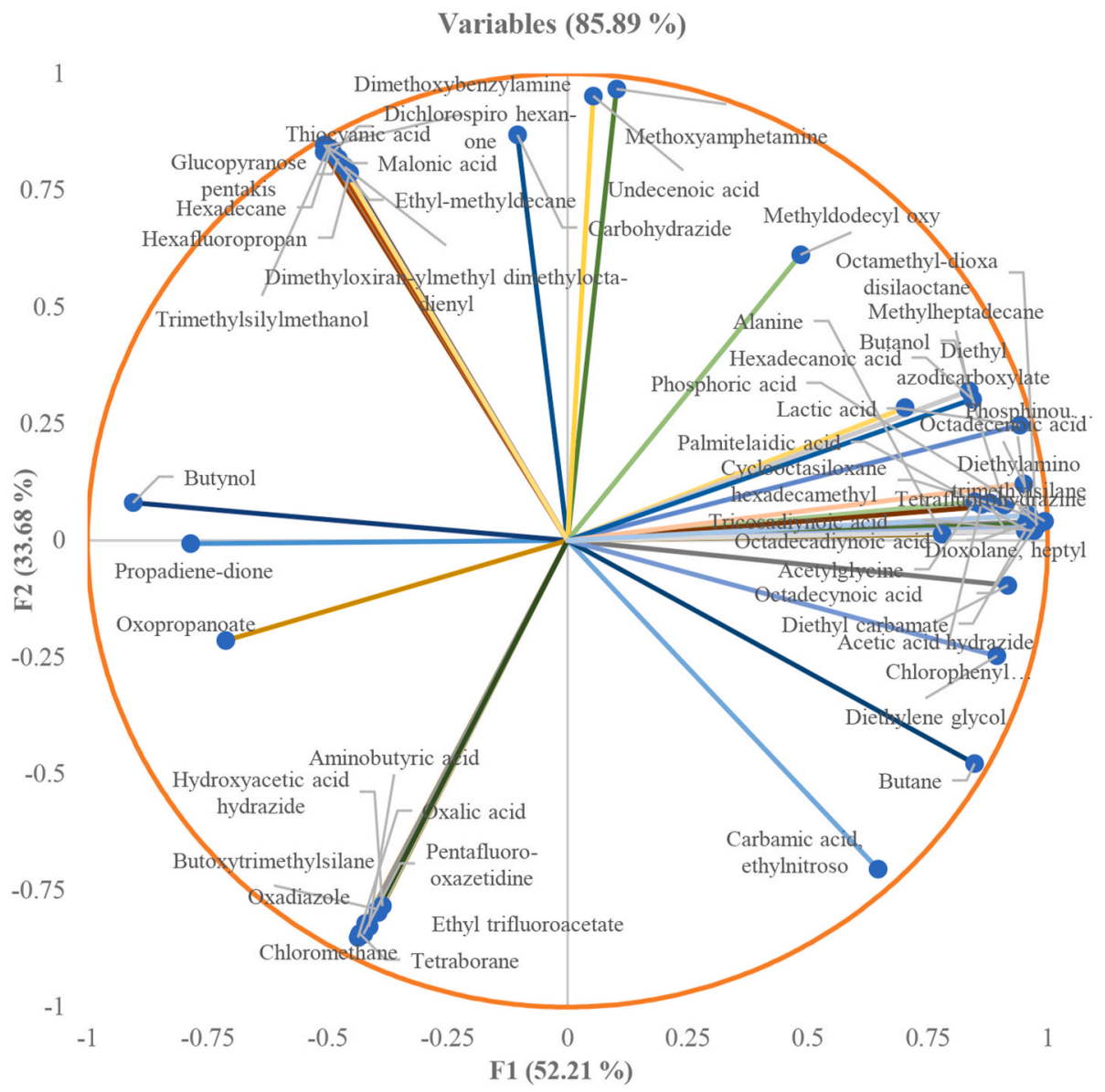

Fig. 2. Plot of loadings formed by the first two principal components from the PCA of intracellular metabolites of untreated HT29 (control), the treated HT29 cells with crude IL-GPE and Taxol. 


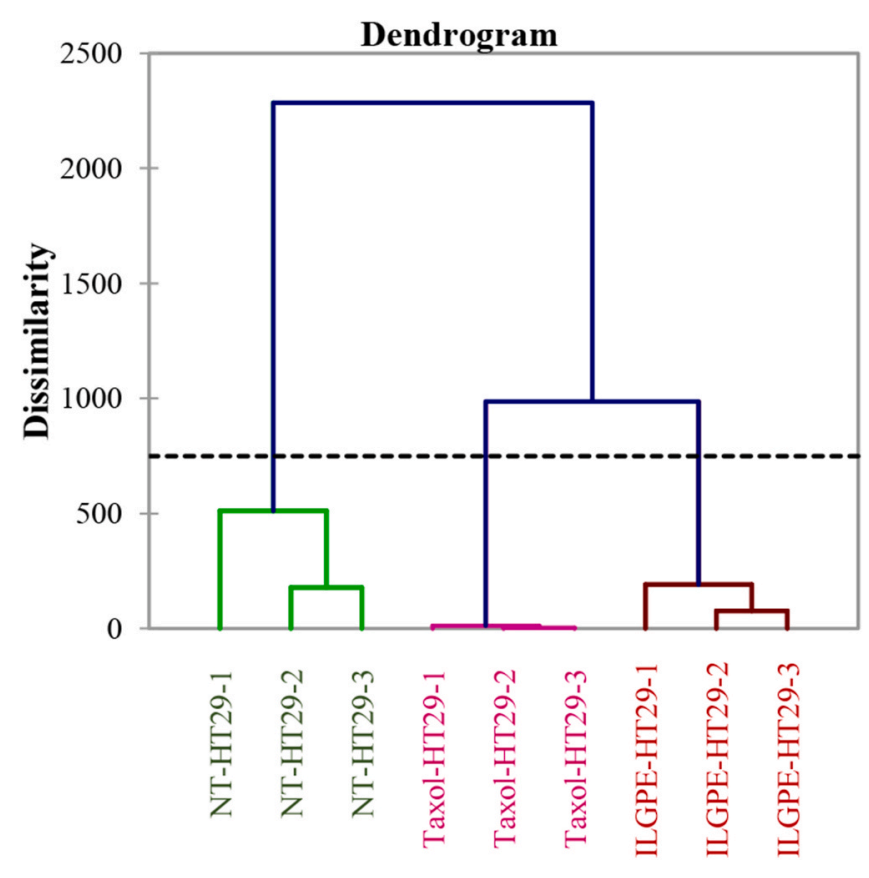

Fig. 3. Agglomerative hierarchical clustering (AHC) dendrogram of intracellular metabolites extracted from the control (NT-HT29) and the treated HT29 cells with crude IL-GPE (IL-GPE-HT29) and Taxol (Taxol-HT29).

reported that the major secondary metabolites in the Annonaceae family known as Annonaceous acetogenins are potent cytotoxic inhibitors of complex I mitochondrial by inhibiting the ubiquinone-linked NADH oxidase of the electron transport chain that is implicated in ATP synthesis (Liaw et al., 2016). The interaction between cell cycle machinery and cell metabolism is bidirectional. The capacity of a cell to join the cell cycle for division depends on the availability of metabolites. In contrast, the cell cycle process is committed to metabolic networks regulation to support cell viability and proliferation (Kaplon et al., 2015). Moreover, cells specifically regulate the eliments of the cell cycle mechanism for the development of the necessary macromolecules during the various stages of the cell cycle.

To explore the mechanisms underlying the activity anticancerous of ionic liquid extract of the Graviola fruit pulp, a presumed concise network for the altered metabolites and their pathways were drawn based on the IPA results and the information from KEGG Pathway
Database (Fig. 4). Upon crude IL-GPE exposure, HT29 cells showed an alteration of amino acid metabolism (Fig. 4) that plays a crucial role in cancer metabolism in which levels of phenethylamine (a derivative of phenylalanine), alanine and its derivative carbamate and hydroxyisobutyrate (a derivative of branched-chain amino acids (BCAA) have downregulated. The nonessential amino acids (NEAA), alanine, arginine, serine and its derivative glycine provide the necessary precursors for the synthesis of lipids, proteins and nucleic acids that are vital to the development of cancer cells. Besides, genetic and functional evidence highlighted that hyperactivation of the serine/glycine metabolism drives oncogenesis (Amelio et al., 2014). Furthermore, alanine metabolism is the competitor of the glucose and glutamine-derived carbon in cancer cells to support the tricarboxylic acid cycle (TCA) as well as NEAA and lipid biosynthesis. The BCAA are vital nutrients for tumour development, and they are being used as an energy supply in many biosynthetic pathways (Ananieva and Wilkinson, 2018). The high enzyme levels in the BCAA metabolic pathways have shown that is linked to the survival and growth of cancer cells (Lee et al., 2019). However, the exact functions of BCAA metabolism in tumour growth remain unknown. This variety of fuel sources reduces the dependence of cancer cells on glucose and serum-derived resources, which are reduced in the microenvironment of the tumour (Sousa et al., 2016).

Besides, the pyruvate has upregulated (Fig. 4) which led to the inhibition of the acetyl CoA biosynthesis after treating HT29 with crude ILGPE. The acetyl CoA is the starting point for the citrate cycle which produces 12 ATP per acetyl group (Akram, 2014). In contrast, lactic acid has been predicted to be activated after treating HT29 with crude IL-GPE, which is an essential energy source in cancer cells. Most cancer cells use aerobic glycolysis to break down sugar, or glucose into smaller molecules by converting pyruvate into lactic acid using lactic acid dehydrogenase-A (LDHA) in order to produce energy (Miranda-Gonçalves et al., 2016). This process produces only 2 ATP per each molecule of glucose, which means that cancerous cells need much more glucose molecules to be consumed from the microenvironment to fulfill energy needs and more lactic acid secrets to maintain cell homeostasis that causes higher acidity of the tumour microenvironment. Thus, this characteristic of cancer cells suppresses penetrated immune cells, which causes tumour immune evasion (Jiang, 2017). Targeting glucose intake and aerobic glycolysis of tumour cells can assure multiple benefits, cancer cell inhibition and recovery of the immune response.

Upon crude IL-GPE exposure, HT29 cells showed an alteration of ketone bodies by upregulating the acetone. Mitochondrial dysfunction is responsible for many cancer metabolic deficiencies and prevents the use of ketone bodies to produce energy in cancer cells (Feng et al., 2019).

Table 2

Summary of the potential metabolic markers and their metabolic pathways for the treated HT29 cells with the crude IL-GPE.

\begin{tabular}{|c|c|c|c|c|c|}
\hline No. & Metabolites & HMDB symbol & Related pathway & Log2(Ratio) & p-value \\
\hline 1 & Butanol & HMDB0004327 & Butanoate metabolism & -3.78 & 0.016 \\
\hline 2 & Phenethylamine & HMDB0012275 & Phenylalanine metabolism & -3.51 & 0.011 \\
\hline 3 & Aceton & HMDB0001659 & $\begin{array}{l}\text { Synthesis and degradation of ketone bodies } \\
\text { Propanoate metabolism }\end{array}$ & 3.41 & 0.023 \\
\hline 4 & Acetylhydrazine & HMDB0060428 & Drug metabolism & -1.83 & 0.017 \\
\hline 5 & D-glucose & HMDB0003345 & Glycolysis/Gluconeogenesis & 0.83 & 0.008 \\
\hline 6 & Amphetamine & HMDB0014328 & Neurotransmitter addiction & 0.24 & 0.026 \\
\hline 7 & Carbamic acid & HMDB0003551 & $\begin{array}{l}\text { Pyrimidine metabolism } \\
\text { Nitrogen metabolism }\end{array}$ & -2.07 & 0.001 \\
\hline 8 & Carbon monoxide & HMDB0001361 & Carbon fixation pathways & 0.83 & 0.042 \\
\hline 9 & Diethylamine & HMDB0041878 & GABA-A receptor agonists/antagonists & -2.51 & 0.000 \\
\hline 10 & Hydroxyisobutyric acid & HMDB0000729 & Valine, isoleucine and leucine degradation & -1.38 & 0.012 \\
\hline 11 & L-alanine & HMDB0000161 & $\begin{array}{l}\text { Methionine and cysteine metabolism } \\
\text { Alanine, glutamate and aspartate metabolism }\end{array}$ & -1.36 & 0.019 \\
\hline 12 & Malonic acid & HMDB0000691 & Inositol phosphate metabolism & 1.09 & 0.000 \\
\hline 13 & Hexadecane & HMDB0033792 & Fatty acid metabolism & 0.48 & 0.001 \\
\hline 14 & Palmitoleic acid & HMDB0012328 & Fatty acid biosynthesis & -1.97 & 0.000 \\
\hline 15 & Phosphate & HMDB0001429 & Pentose phosphate pathway & -1.74 & 0.000 \\
\hline 16 & Thiocyanate & HMDB0001453 & Thiosulfate metabolism & 2.47 & 0.000 \\
\hline 17 & Urea & HMDB0000294 & Urea Cycle & 1.06 & 0.053 \\
\hline
\end{tabular}




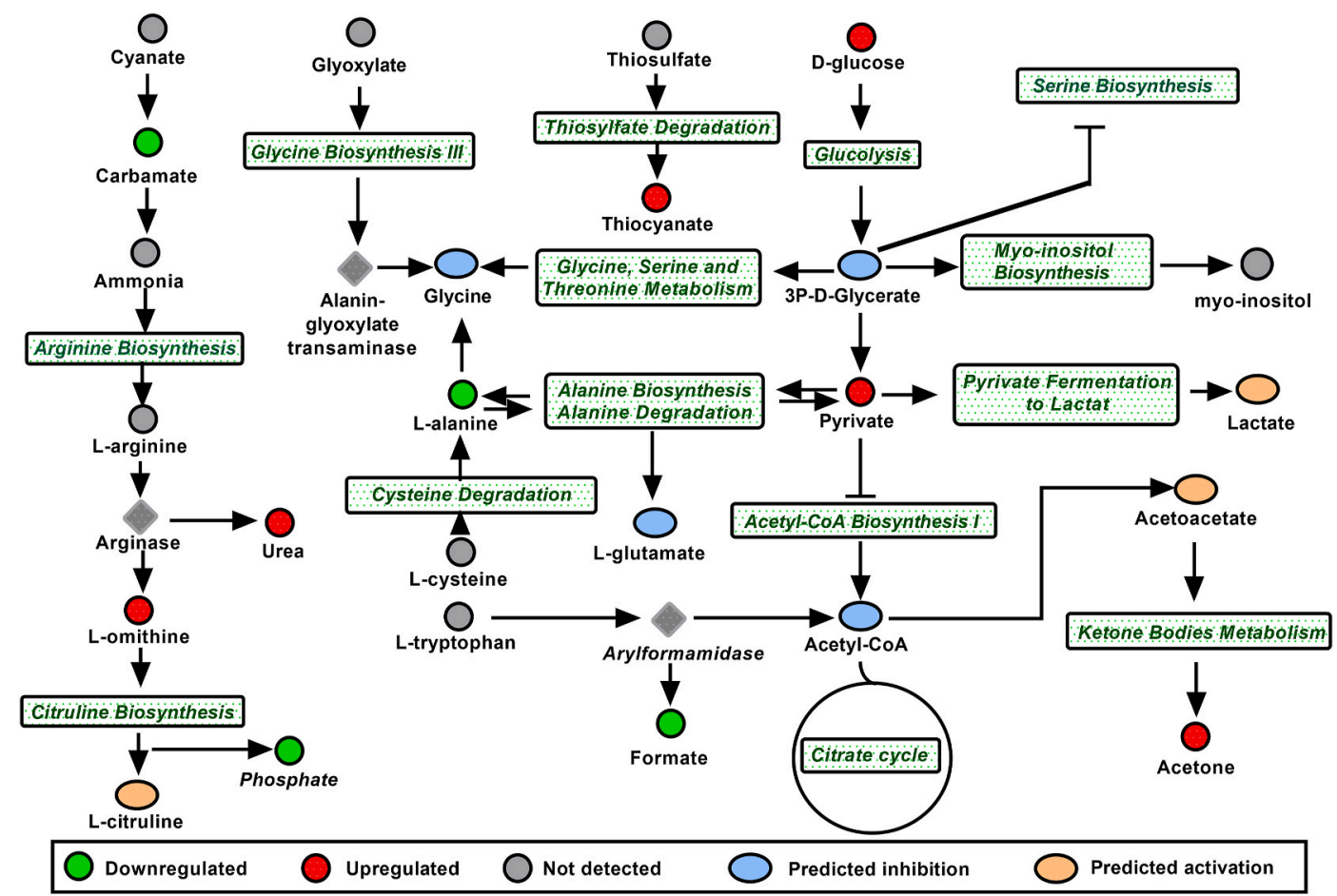

Fig. 4. Schematic overview of the major metabolites and their altered pathways in the crude IL-GPE treated HT29 cells. The upregulated and downregulated metabolites are presented in red and green colored circles, respectively. The non-detected metabolites are shown in grey colored circles and the predicted activation and inhibition activity by IPA are shown in oval brown and blue circles, respectively. Pathways' names are mentioned in italic green words. (For interpretation of the references to color in this figure legend, the reader is referred to the Web version of this article.)

Previous experiments have demonstrated that, unlike normal tissue, tumour cells can not efficiently utilise ketone bodies to produce energy. In addition, ketones suppress the viability and spread of cultured cancer cells in which the ketone supplement reduced the proliferation of in vitro-grown VM-M3 cells and extended the lifespan of mice with metastatic cancer (Poff et al., 2014), even in the presence of elevated glucose levels. Furthermore, the urea cycle (UC) was altered when treated HT29 cells with IL-GPE by upregulating the L-omithine and urea. The UC is the primary mechanism whereby mammalians discard nitrogen waste. Specific alterations in the appearance of so many UC enzymes are found to exist in many tumours, leading to different metabolic markers called "UC dysregulation". Lee and co-workers (Lee et al., 2018) suggested that UCD is a typical characteristic of tumours that significantly influences the reactions of mutagenesis, carcinogenesis and immunotherapy as well as the association with increased response to immunocompromising therapy.

\section{Conclusion}

The GC-TOFMS metabolomics analysis of intracellular metabolites of HT29 cells in response to crude IL-GPE treatment was conducted and compared to Taxol. The result of agglomerative hierarchical clustering has separated between the control group and the treated HT29 cells with crude IL-GPE and Taxol. Moreover, the pathway analysis of metabolomic profiles showed an alteration of many metabolic pathways including amino acid metabolism, aerobic glycolysis, urea cycle and ketone bodies metabolism that contribute to energy metabolism and cancer cells proliferation. Thus, the Graviola fruit pulp is a promising alternative or complementary supplement towards reducing colon cancer growth.

\section{Author's contribution}

All authors contributed to the study conception and design. Material preparation, data collection and analysis were performed by [Djabir Daddiouaissa], [Azura Amid], [Muhamad Shirwan Abdullah Sani] and [Ahmed A. M. Elnour]. The first draft of the manuscript was written by [Djabir Daddiouaissa] and all authors commented on previous versions of the manuscript. All authors read and approved the final manuscript.

\section{Declaration of competing interest}

No conflict of interest was declared.

\section{Acknowledgement}

This research work was supported by the International Islamic University Malaysia Research Initiative Grant Scheme (P-RIGS18-0650065).

\section{References}

Akram, M., 2014. Citric acid cycle and role of its intermediates in metabolism. Cell Biochem. Biophys. 68 (3), 475-478.

Alessandro, A., Zolla, L., 2012. Metabolomics and cancer drug discovery: let the cells do the talking. Drug Discov. Today 17 (1-2), 3-9.

Amelio, I., Cutruzzolá, F., Antonov, A., Agostini, M., Melino, G., 2014. Serine and glycine metabolism in cancer. Trends Biochem. Sci. 39 (4), 191-198.

Ananieva, E.A., Wilkinson, A.C., 2018. Branched-chain amino acid metabolism in cancer. Curr. Opin. Clin. Nutr. Metab. Care 21 (1), 64-70.

Betancur-Galvis, L.A., Saez, J., Granados, H., Salazar, A., Ossa, J.E., 1999. Antitumor and antiviral activity of Colombian medicinal plant extracts. Mem. Inst. Oswaldo Cruz 94 (4), 531-535.

Cao, B., Aa, J., Wang, G., Wu, X., Liu, L., Li, M., Shi, J., Wang, X., Zhao, C., Zheng, T., 2011. GC-TOFMS analysis of metabolites in adherent MDCK cells and a novel strategy for identifying intracellular metabolic markers for use as cell amount indicators in data normalization. Anal. Bioanal. Chem. 400 (9), 2983-2993.

Coe, F.G., 2008. Rama midwifery in eastern Nicaragua. J. Ethnopharmacol. 117 (1), 136-157.

Daddiouaissa, D., Amid, A., 2018. Anticancer activity of acetogenins from Annona muricata fruit. IIUM Medical Journal Malaysia 17 (3).

Daddiouaissa, D., Amid, A., Kabbashi, N.A., Fuad, F.A., Elnour, A.M., Epandy, M.A., 2019. Antiproliferative activity of ionic liquid-graviola fruit extract against human 
breast cancer (MCF-7) cell lines using flow cytometry techniques. J. Ethnopharmacol. 236, 466-473.

Daddiouaissa, D., Amid, A., Shirwan, M.A., Elnour, A.M., 2020. Phytochemical analysis of ionic liquid-Graviola (Annona muricata) fruit extract and its acute toxicity on zebrafish early-life stages. Asia Pac. J. Mol. Biol. Biotechnol. 28 (2), 113-124.

Dai, Y., Hogan, S., Schmelz, E.M., Ju, Y.H., Canning, C., Zhou, K., 2011. Selective growth inhibition of human breast cancer cells by graviola fruit extract in vitro and in vivo involving downregulation of EGFR expression. Nutr. Canc. 63 (5), 795-801.

Dal Molin, G.T., Cavinatto, A., Cruz, V.E., Schneider, A., Colet, C., 2012. Utilização de plantas medicinaise fitoterápicos por pacientes submetidos à quimioterapia de um centro de oncologia de ijuí/rs/The use of medicinal plants and herbal medicines for patients in chemotherapy in an oncology center of Ijuí/RS. Revista Contexto \& Saúde 12 (22), 50-51.

Dash, M., Liu, H., Scheuermann, P., Tan, K.L., 2003. Fast hierarchical clustering and its validation. Data Knowl. Eng. 44 (1), 109-138.

Feng, S., Wang, H., Liu, J., Aa, J., Zhou, F., Wang, G., 2019. Multi-dimensional roles of ketone bodies in cancer biology: opportunities for cancer therapy. Pharmacol. Res. $150,104500$.

Fernie, A.R., Trethewey, R.N., Krotzky, A.J., Willmitzer, L., 2004. Metabolite profiling: from diagnostics to systems biology. Nat. Rev. Mol. Cell Biol. 5 (9), 763-769.

Gagaoua, M., Bonnet, M., De Koning, L., Picard, B., 2018. Reverse Phase Protein array for the quantification and validation of protein biomarkers of beef qualities: the case of meat color from Charolais breed. Meat Sci. 145, 308-319.

Gavamukulya, Y., Abou-Elella, F., Wamunyokoli, F., AEl-Shemy, H., 2014. Phytochemical screening, anti-oxidant activity and in vitro anticancer potential of ethanolic and water leaves extracts of Annona muricata (Graviola). Asian Pacific journal of tropical medicine 7, S355-S363.

George, V.C., Kumar, D., Rajkumar, V., Suresh, P., Kumar, R.A., 2012. Quantitative assessment of the relative antineoplastic potential of the n-butanolic leaf extract of Annona muricata Linn. in normal and immortalized human cell lines. Asian Pac. J. Cancer Prev. APJCP 13 (2), 699-704.

Granato, D., Santos, J.S., Escher, G.B., Ferreira, B.L., Maggio, R.M., 2018. Use of principal component analysis (PCA) and hierarchical cluster analysis (HCA) for multivariate association between bioactive compounds and functional properties in foods: a critical perspective. Trends Food Sci. Technol. 72, 83-90.

Gyamfi, K., Sarfo, D., Nyarko, B., Akaho, E., Serfor-Armah, Y., Ampomah-Amoako, E., 2011. Assessment of elemental content in the fruit of graviola plant, Annona muricata, from some selected communities in Ghana by instrumental neutron activation analysis. Elixir Food Sci 41, 5671-5675.

Jang, Z.-H., Chung, H.-C., Ahn, Y.G., Kwon, Y.-K., Kim, J.-S., Ryu, J.-H., Kim, C.-H., Hwang, G.-S., 2012. Metabolic profiling of an alcoholic fatty liver in zebrafish (Danio rerio). Mol. Biosyst. 8 (7), 2001-2009.

Jiang, B., 2017. Aerobic glycolysis and high level of lactate in cancer metabolism and microenvironment. Genes \& diseases 4 (1), 25-27.

Kaplon, J., van Dam, L., Peeper, D., 2015. Two-way communication between the metabolic and cell cycle machineries: the molecular basis. Cell Cycle 14 (13), 2022-2032.

Kouznetsova, V.L., Kim, E., Romm, E.L., Zhu, A., Tsigelny, I.F., 2019. Recognition of early and late stages of bladder cancer using metabolites and machine learning. Metabolomics 15 (7), 94.

Lee, J.H., Cho, Y.-r., Kim, J.H., Kim, J., Nam, H.Y., Kim, S.W., Son, J., 2019. Branchedchain amino acids sustain pancreatic cancer growth by regulating lipid metabolism. Exp. Mol. Med. 51 (11), 1-11.

Lee, J.S., Adler, L., Karathia, H., Carmel, N., Rabinovich, S., Auslander, N., Keshet, R., Stettner, N., Silberman, A., Agemy, L., Helbling, D., Eilam, R., Sun, Q., Brandis, A. Malitsky, S., Itkin, M., Weiss, H., Pinto, S., Kalaora, S., Levy, R., Barnea, E., Admon, A., Dimmock, D., Stern-Ginossar, N., Scherz, A., Nagamani, S.C.S., Unda, M., Wilson, D.M., Elhasid, R., Carracedo, A., Samuels, Y., Hannenhalli, S., Ruppin, E., Erez, A., 2018. Urea cycle dysregulation generates clinically relevant genomic and biochemical signatures. Cell 174 (6), 1559-1570 e1522.

Li, Y., Ruan, Q., Li, Y., Ye, G., Lu, X., Lin, X., Xu, G., 2012. A novel approach to transforming a non-targeted metabolic profiling method to a pseudo-targeted method using the retention time locking gas chromatography/mass spectrometryselected ions monitoring. J. Chromatogr. A 1255, 228-236.

Liaw, C.-C., Liou, J.-R., Wu, T.-Y., Chang, F.-R., Wu, Y.-C., 2016. Acetogenins from Annonaceae, Progress in the Chemistry of Organic Natural Products 101. Springer, pp. 113-230.
Liu, Y., Lu, S., Zhao, L., Dong, X., Zhu, Z., Jin, Y., Chen, H., Lu, F., Hong, Z., Chai, Y., 2018. Effects of glaucocalyxin A on human liver cancer cells as revealed by GC/MSand LC/MS-based metabolic profiling. Anal. Bioanal. Chem. 410 (14), 3325-3335.

Magadi, V.P., Ravi, V., Anantharaju Arpitha, L., Kumaraswamy, K., Manjunath, K., 2015. Evaluation of cytotoxicity of aqueous extract of Graviola leaves on squamous cell carcinoma cell-25 cell lines by 3-(4, 5-dimethylthiazol-2-Yl)-2, 5

diphenyltetrazolium bromide assay and determination of percentage of cell inhibition at G2M phase of cell cycle by flow cytometry: an in vitro study. Contemp. Clin. Dent. 6 (4), 529.

Maratu, S., Amalia, S., Evika, H., 2020. Antioxidant Activity of Extract Cantigi (Vaccinium Varingiaefolium) (Bl.) Miq and its Major Compound of GC MS NIST Library Analysis, 4th International Symposium on Health Research (ISHR 2019). Atlantis Press, pp. 553-558.

Martinez-Outschoorn, U.E., Peiris-Pagés, M., Pestell, R.G., Sotgia, F., Lisanti, M.P., 2017. Cancer metabolism: a therapeutic perspective. Nat. Rev. Clin. Oncol. 14 (1), 11-31.

Miranda-Gonçalves, V., Granja, S., Martinho, O., Honavar, M., Pojo, M., Costa, B.M., Pires, M.M., Pinheiro, C., Cordeiro, M., Bebiano, G., 2016. Hypoxia-mediated upregulation of MCT1 expression supports the glycolytic phenotype of glioblastomas. Oncotarget 7 (29), 46335.

Mishra, P., Gong, Z., Kelly, B.C., 2017. Assessing biological effects of fluoxetine in developing zebrafish embryos using gas chromatography-mass spectrometry based metabolomics. Chemosphere 188, 157-167.

Monigatti, M., Bussmann, R.W., Weckerle, C.S., 2013. Medicinal plant use in two Andean communities located at different altitudes in the Bolívar Province, Peru. J. Ethnopharmacol. 145 (2), 450-464.

Muhamad, S., Jamilah, B., Russly, A., Faridah, A., 2017. In vitro antibacterial activities and composition of Carica papaya cv. Sekaki/Hong Kong peel extracts. International Food Research Journal 24 (3).

Paul, J., Gnanam, R., M Jayadeepa, R., Arul, L., 2013. Anti cancer activity on Graviola, an exciting medicinal plant extract vs various cancer cell lines and a detailed computational study on its potent anti-cancerous leads. Curr. Top. Med. Chem. 13 (14), 1666-1673.

Poff, A.M., Ari, C., Arnold, P., Seyfried, T.N., D'Agostino, D.P., 2014. Ketone supplementation decreases tumor cell viability and prolongs survival of mice with metastatic cancer. Int. J. Canc. 135 (7), 1711-1720.

Ramirez, T., Daneshian, M., Kamp, H., Bois, F.Y., Clench, M.R., Coen, M., Donley, B., Fischer, S.M., Ekman, D.R., Fabian, E., 2013. Metabolomics in toxicology and preclinical research. ALTEX 30 (2), 209.

Ringnér, M., 2008. What is principal component analysis? Nat. Biotechnol. 26 (3), 303-304.

Samuel, A.J.S.J., Kalusalingam, A., Chellappan, D.K., Gopinath, R., Radhamani, S., Husain, H.A., Muruganandham, V., Promwichit, P., 2010. Ethnomedical survey of plants used by the orang asli in kampung bawong, Perak, west Malaysia. J. Ethnobiol. Ethnomed. 6 (1), 5.

Siegel, R.L., Miller, K.D., Goding Sauer, A., Fedewa, S.A., Butterly, L.F., Anderson, J.C., Cercek, A., Smith, R.A., Jemal, A., 2020. Colorectal cancer statistics, 2020. CA. A Cancer Journal for Clinicians 70 (3), 145-164.

Sousa, C.M., Biancur, D.E., Wang, X., Halbrook, C.J., Sherman, M.H., Zhang, L., Kremer, D., Hwang, R.F., Witkiewicz, A.K., Ying, H., 2016. Pancreatic stellate cells support tumour metabolism through autophagic alanine secretion. Nature 536 (7617), 479-483.

Tan, Y., Yin, P., Tang, L., Xing, W., Huang, Q., Cao, D., Zhao, X., Wang, W., Lu, X., Xu, Z., 2012. Metabolomics study of stepwise hepatocarcinogenesis from the model rats to patients: potential biomarkers effective for small hepatocellular carcinoma diagnosis. Mol. Cell. Proteomics 11 (2).

Taylor, L., 2002. Graviola. Technical Data Report for Graviola, Annona Muricata, second ed. Sage Press, Inc., Herbal Secrets of the Rainforest.

Weiner, J., Mohney, R.P., Kaufmann, S.H., 2018. The Potential of Metabolic Profiling for Vaccine Development, Seminars in Immunology. Elsevier, pp. 44-51.

Xiao, Z., Dai, S., Niu, Y., Yu, H., Zhu, J., Tian, H., Gu, Y., 2011. Discrimination of Chinese vinegars based on headspace solid-phase microextraction-gas chromatography mass spectrometry of volatile compounds and multivariate analysis. J. Food Sci. 76 (8), C1125-C1135.

Yajid, A.I., Ab Rahman, H.S., Wong, M.P.K., Zain, W.Z.W., 2018. Potential benefits of Annona muricata in combating cancer: a review. Malays. J. Med. Sci.: MJMS 25 (1), 5.

Zhao, Y., Butler, E.B., Tan, M., 2013. Targeting cellular metabolism to improve cancer therapeutics. Cell Death Dis. 4 (3) e532-e532. 